\title{
Correction to: Polypharmacy definition and prevalence in heart failure: a systematic review
}

\author{
Janine Beezer ${ }^{1,2} \cdot$ Manal Al Hatrushi ${ }^{3} \cdot$ Andy Husband $^{2} \cdot$ Amanj Kurdi $^{4,5} \cdot$ Paul Forsyth $^{6}$ \\ Accepted: 14 July 2021 / Published online: 31 July 2021 \\ ๑) The Author(s), under exclusive licence to Springer Science+Business Media, LLC, part of Springer Nature 20212021

\section{Correction to: Heart Failure Reviews https://doi.org/10.1007/s10741-021-10135-4}

In the original version of the article, unfortunately, the one of the authors name is incorrect. The third author should read Andy Husband NOT Andy HusbandSlovaki.

The original article has been corrected.

Publisher's Note Springer Nature remains neutral with regard to jurisdictional claims in published maps and institutional affiliations.

The original article can be found online at https://doi.org/10.1007/ s10741-021-10135-4.

Janine Beezer

janine.beezer@newcastle.ac.uk

1 Inpatient Pharmacy Department, South Tyneside and Sunderland Foundation Trust (Pharmacy), Kayll Road, Sunderland SR7 8DE, UK

2 School of Pharmacy, Newcastle University, Newcastle, UK

3 Sultan Qaboos University Hospital (Pharmacy), Muscat, Oman

4 Strathclyde Institute of Pharmacy and Biomedical Science, University of Strathclyde, Glasgow, UK

5 Department of Pharmacology and Toxicology, College of Pharmacy, Hawler Medical Univeristy, Erbil, Iraq

6 NHS Greater Glasgow and Clyde, Glasgow, UK 